\title{
Attenuation of Carbon Tetrachloride - Induced Hepatoxicity by Dacryodes edulis Seeds Ethanolic Extract in Male Wistar Rats
}

\author{
George O. Eidangbe ${ }^{1}$, Ikechukwu O. Obasi ${ }^{2}$, Antoinette C. Okaka ${ }^{2}$, Rachel C. Eidangbe ${ }^{3}$, \\ Olarewaju M. Oluba ${ }^{3, *(D)}$
}

1 Department of Medical Biochemistry, College of Medicine, Ambrose Alli University, Ekpoma, Edo State, Nigeria

2 Department of Applied Biochemistry, Nnamdi Azikiwe University, Awka, Anambra State, Nigeria

3 Department of Nursing Sciences, College of Medicine Ambrose Alli University, Ekpoma, Edo State, Nigeria

4 Food Safety and Toxicology Research Unit, Department of Biochemistry, College of Pure \& Applied Sciences, Landmark University, Omu-Aran, Nigeria

* Correspondence: oluba.olarewaju@1mu.edu.ng; olubamike2000@yahoo.co.uk;

Scopus Author ID 22635831000

Received: 17.08.2020; Revised: 9.09.2020; Accepted: 11.09.2020; Published: 13.09.2020

\begin{abstract}
Dacryodes edulis (African pear) seed has a long history of use in ethnomedicine. However, there is a paucity of information on its ameliorative potential on hepatic damage. In the present study, the potentials of $D$. edulis ethanolic seed extract (DET) in attenuating carbon tetrachloride $\left(\mathrm{CCl}_{4}\right)$ induced hepatotoxicity in male Wistar rats was assessed. Ninety male Wistar rats were divided into 3 groups $(n=10)$ designated: control, $\mathrm{CCl}_{4}$, and DET, respectively. Animals in the control group were administered $2 \mathrm{~mL} / \mathrm{kg}$ body weight corn oil, while those assigned to $\mathrm{CCl}_{4}$ and DET groups were administered i.p. $30 \% \mathrm{CCl}_{4}$ in corn oil $(1: 1 \mathrm{v} / \mathrm{v})$ at $2 \mathrm{~mL} / \mathrm{kg}$. Treatment was administered once every 24 $\mathrm{h}$ consecutively for $72 \mathrm{~h}$. Thereafter, control and $\mathrm{CCl}_{4}$ groups were treated once daily with $1 \mathrm{~mL}$ distilled water by gavage, while DET rats were treated once daily with $1500 \mathrm{mg} / \mathrm{kg}$ DET by gavage. At every 7 days interval and for 28 consecutive days, animals were starved overnight, weighed, and six rats from each group were sacrificed under anesthesia to collect blood and liver samples. After 28 days, remarkable improvements in feed intake, body weight, serum levels of hepatic function indicators, and hepatic histology were observed in DET rats compared to $\mathrm{CCl}_{4}$ rats. These results suggest a possible ameliorative potential of D. edulis ethanolic seed extract against $\mathrm{CCl}_{4}$-induced hepatic injury.
\end{abstract}

Keywords: Dacryodes edulis; carbon tetrachloride; hepatotoxicity; ethanolic seed extract; hepatic parameters.

(C) 2020 by the authors. This article is an open-access article distributed under the terms and conditions of the Creative Commons Attribution (CC BY) license (https://creativecommons.org/licenses/by/4.0/).

\section{Introduction}

Oxidative stress elicits a cell response, which in turn is a function of the severity as well as the type of insult by altering cellular homeostasis. By implication, there subsists a constraining stress threshold below which cells elicit protective mechanisms designed to ascertain survival. However, stress above this safety or protective threshold leads to the activation of alternative signaling pathways culminating in apoptosis, necrosis, pyroptosis, or autophagic cell death [1,2]. It is thus implied that cell survival is premised on a balance between oxidant and antioxidant species. The attainment and maintenance of this equilibrium are mediated by cellular molecules and enzymes responsible for the metabolism or neutralization of reactive oxygen species.

Free radicals are highly reactive small molecular species characterized by an unpaired electron in their outermost orbital. Reactive oxygen species are generated by several 
environmental agents ranging from chemical contaminants, cigarette smoke, ultra-violent light [3]. Nonetheless, these cellular stressors are also products of normal essential cellular reactions ranging from incomplete catabolism, hepatic detoxification, or mitochondrial energy production. An overwhelming generation of these oxidative agents against cellular innate defense mechanisms often leads to pronounced damage to cellular macromolecules such as membrane lipids, proteins or enzymes, carbohydrates, and DNA [4,5]. Thus, oxidative stress and its attendant complications have been implicated in the underlying pathology of several ailments, including neurodegenerative and cardiovascular diseases, cancer, diabetes, and autoimmune disorders in humans [6,7].

Due to the reported side effects coupled with the associated cost on the use of orthodox medicine in ameliorating compromised liver function, there is a renewed effort in the discovery of a more effective, safe, and affordable drugs. More recently, research attention has increasingly focused on the evaluation of acclaimed traditional African herbal plant extracts and the elucidation of the scientific basis underlying their medicinal activity [8,9]. The verse majority of the population in sub-Saharan Africa relies on plants as a remedy against sicknesses and diseases. The potency of some of these plant extracts against diseases such as fever, malaria, diabetes mellitus, cardiovascular diseases, liver failure, etc. has been demonstrated using both in vitro and in vivo assays.

Dacryodes edulis, also known as African pear, is an evergreen perennial tree that belongs to the Buseraseae family. It is believed to originate from central Africa and the Gulf of Guinea from where it spreads to West Africa. It has enjoyed a broad spectrum of usage in African ethnomedicine. The various parts of the plant have been utilized in the treatment of varying diseases. The bark is employed in wound healing [10], as well as in managing diseases such as leprosy, dysentery, anemia, hemoptysis, debility, and skin diseases. Extract from the leaves is used in the treatment of skin diseases, including scabies, ringworm, rash, and wound. In addition, the leaf extract is used in the treatment of ear infection, malaria, and as an antipyretic agent. In combination with kolanut extract, juice extracted from the stem is deployed as an antiemetic [11,12].

Carbon tetrachloride, $\mathrm{CCl}_{4}$, is a well-known hepatotoxin with a presence in water, air, and soil. Asides its presence in the environment, there has been reported occupational exposure to $\mathrm{CCl}_{4}$ in the chemical industry, laboratories to mention but a few. Severe pathological changes in hepatocytes due to $\mathrm{CCl}_{4}$ have been reported even at doses as low as $5 \mathrm{ppm}$ $\left(32 \mathrm{mg} / \mathrm{m}^{3}\right)$ [13,14]. Over the years, $\mathrm{CCl}_{4}$ has been widely used in the preclinical model of xenobiotic-induced hepatotoxicity. The reported hepatotoxic effect of $\mathrm{CCl}_{4}$ is thought to be mediated through its ability to initiate the generation of free radicals through its conversion by cytochrome $\mathrm{P}_{450}$ enzymes into the highly reactive trichloromethyl radical, thus potentiating hepatocyte membrane lipid peroxidation leading to liver injury $[15,16]$. The present study was intended to validate the effects of oral administration of ethanolic extract of Dacryodes edulis seeds on carbon tetrachloride-induced hepatotoxicity in male Wistar rats.

\section{Materials and Methods}

\subsection{Chemicals and reagents.}

Chemicals and reagents used were of analytical grades and were products of Merck Life Science UK Ltd. (Gillingham, United Kingdom) unless otherwise specified. 


\subsection{Plant material.}

Matured seeds of Dacryodes edulis were collected from the vegetation area around Awka, Anambra State, Nigeria, within the months of May and June. The plant sample was identified and authenticated at the Department of Botany, Ambrose Alli University, Ekpoma, Nigeria, where the specimen was deposited.

\subsection{Animals and treatments.}

Male Wistar rats weighing 180 - $200 \mathrm{~g}$ were obtained from the College of Medicine, Ambrose Alli University, Ekpoma (Nigeria) animal house. The animals were kept in standard rat cages under a controlled environment with a $12 \mathrm{~h}$ light/dark cycle and fed ad libitum with unrestricted access to water. Prior authorization for animal handling was sought from Ambrose Alli University, Ekpoma, Nigeria Research, and Ethics Committee (approval number AAU/EA/1134/2019). The care and handling of animals complied strictly with the National Institutes of Health Manual on care and use of laboratory animals [17].

\subsection{Extract preparation.}

The plant sample was washed with copious water and cut into small pieces and allowed to dry at ambient temperature for 2 weeks. The dried seed sample was milled into a fine powder using a mechanical mill and then kept in a dried air-tight container before being stored at $4{ }^{\circ} \mathrm{C}$ until required for further analysis. Ten grams $(10 \mathrm{~g})$ of the powdered sample was extracted with $100 \mathrm{~mL}$ ethanol for 24 hours using Soxhlet apparatus at $78 \pm 2{ }^{\circ} \mathrm{C}$. The extract was freeze-dried in a vacuum freeze dryer (Lyotrap, LTE Scientific Ltd., Greenfield, Oldham, UK) at $-70^{\circ} \mathrm{C}$. The concentrated ethanolic extract was kept in a sealed amber bottle at $4{ }^{\circ} \mathrm{C}$ until required for further analysis.

\subsection{Median lethal dose determination.}

Prior experiments to access the acute toxicity of the extract was carried out by the method described by Lorke [18] with minor modifications. The experiment was carried out in two phases. In the first (A) phase, 9 rats were subdivided into 3 groups $(n=3)$, namely AI, AII, and AIII, and were administered 10,100, and $1000 \mathrm{mg} / \mathrm{kg}$, respectively, D. edulis ethanolic seed extract by gavage. Thereafter, animals in each group were observed for 24 hours for any death. The second phase (B) was carried out based on the outcome of the first phase. This consisted of another three groups designated: BI, BII, and BIII of one rat each and was administered the extract at 1500,3000, and $5000 \mathrm{mg} / \mathrm{kg}$ body weight, respectively, and observed for signs of abnormal behavior or death. The mean value of the highest dose that did not pose any lethality to the rat and the lowest safe dose was computed to give the mean lethal dose (LD50).

\subsection{Carbon-tetrachloride-induced hepatotoxicity.}

Sixty (60) male Wistar rats were randomly divided into 3 groups $(n=30)$ designated: Control (negative): administered intraperitoneal (i.p.) injection of $0.2 \mathrm{~mL} / 100 \mathrm{~g}$ body weight corn oil once every $24 \mathrm{~h}$ consecutively for $72 \mathrm{~h} ; \mathrm{CCl}_{4}$ (served as positive control): administered i.p. $30 \% \mathrm{CCl}_{4}$ in corn oil $(1: 1 \mathrm{v} / \mathrm{v})$ at $0.2 \mathrm{~mL} / 100 \mathrm{~g}$ body weight once every $24 \mathrm{~h}$ consecutively for $72 \mathrm{~h}$; DET: administered i.p. $30 \% \mathrm{CCl}_{4}$ in corn oil $(1: 1 \mathrm{v} / \mathrm{v})$ at $0.2 \mathrm{~mL} / 100 \mathrm{~g}$ body weight 
once every $24 \mathrm{~h}$ consecutively for $72 \mathrm{~h}$. Following $\mathrm{CCl}_{4}$ intoxication, animals in each group were fasted overnight, weighed, and placed on their respective treatment as follows: Control: $1 \mathrm{~mL}$ distilled water administered orally by gavage; $\mathrm{CCl}_{4}: 1 \mathrm{~mL}$ distilled water administered orally by gavage; DET: $1500 \mathrm{mg} / \mathrm{kg}$ body weight DET administered orally by gavage.

Treatment was given once daily. At weekly intervals (days $0,7,14,21$, and 28), animals were starved overnight, weighed and six rats from each group were sacrificed under anesthesia, blood and liver samples were quickly collected. The liver was blotted, freed of extraneous tissues, and weighed.

\subsection{Biochemical analysis.}

The serum was prepared from the whole blood sample centrifuged for $10 \mathrm{~min}$ at 3000 rpm. Serum was collected into clean, dry plain tubes and used for biochemical analyses. Alkaline phosphatase (ALP) was estimated by the $p$-nitrophenol method of Bomers and McComb [19] while Aspartate aminotransaminase (AST) and Alanine aminotransaminase (ALT) were estimated by the method of Reitmans and Frankel [20]. Total bilirubin and conjugated bilirubin were estimated enzymatic method based on the procedures described by Perry et al. [21] and Kurosaka et al. [22], respectively. Total serum protein was estimated by the Biuret method as described by Ohnishi and Barr [23] while albumin was estimated by the bromocresol purple method of Ueno et al. [24].

\subsection{Histological evaluation.}

A small portion of the liver sample was cut and fixed in $10 \%$ neutral buffered formalin. Thin sections of $5 \mu \mathrm{m}$ were taken using a rotary microtone, stained with hematoxylin and eosin for light microscopy. The slides were viewed at an appropriate objective to check for the architecture of the tissues. The pictures were displayed in photomicrographs, and the histology was analyzed.

\subsection{Statistical analysis.}

Results were expressed as mean \pm SEM. Statistical analysis and graphical representation were carried out using GraphPad Prism software (Version 8.0). A mean comparison was by one-way analysis of variance (ANOVA) followed by the Least Significant Difference (LSD) test. $P$ values less than 0.05 were considered significant.

\section{Results and Discussion}

\subsection{Acute toxicity.}

Dacryodes edulis ethanol seed extract at doses ranging from $10 \mathrm{mg} / \mathrm{kg}$ to $5000 \mathrm{mg} / \mathrm{kg}$ body weight in rats was considered safe considering the fact that no mortality or variation in physical appearance or behavior occurred following a $24 \mathrm{~h}$ administration (Table 1).

Table 1. Oral acute toxicity of ethanol seed extract of Dacryodes edulis.

\begin{tabular}{|c|c|c|c|c|}
\hline Treatment & $n$ & Dose (mg/kg body weight) & Mortality & Other symptoms \\
\hline \multicolumn{5}{|l|}{ Phase A } \\
\hline \multirow{3}{*}{$\begin{array}{l}\text { AI } \\
\text { AII } \\
\text { AIII }\end{array}$} & 3 & 10 & Nil & Nil \\
\hline & 3 & 100 & Nil & Nil \\
\hline & 3 & 1000 & Nil & Nil \\
\hline \multirow{2}{*}{$\begin{array}{l}\text { Phase B } \\
\text { BI }\end{array}$} & & & & \\
\hline & 1 & 1500 & Nil & Nil \\
\hline
\end{tabular}




\begin{tabular}{l|l|l|l|l} 
Treatment & $\boldsymbol{n}$ & Dose $(\mathbf{m g} / \mathbf{k g}$ body weight $)$ & Mortality & Other symptoms \\
\hline \multirow{2}{*}{ BII } & 1 & 3000 & Nil & Nil \\
\cline { 2 - 5 } & 1 & 5000 & Nil & Nil
\end{tabular}

\subsection{Effects on feed intake and body weight.}

Feed intake was significantly $(p<0.05)$ reduced in the $\mathrm{CCl}_{4}$-induced but untreated rats compared to control (Figure 1a) all through the 28-day study period. Remarkable improvement in feed intake was observed in $\mathrm{CCl}_{4}$-induced rats treated with $1500 \mathrm{mg} / \mathrm{kg}$ ethanolic seed extract of D. edulis compared to $\mathrm{CCl}_{4}$-induced but untreated rats (Figure 1b).
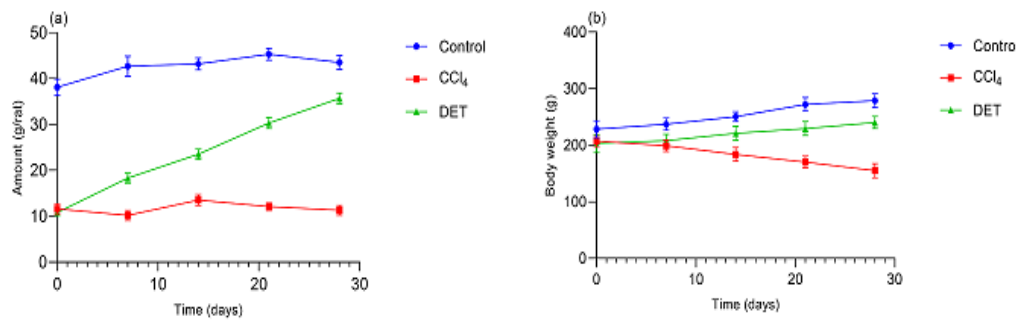

Figure 1. Feed intake (a) and body weight of rats intoxicated with $\mathrm{CCl}_{4}$ and treated with ethanol seed extract of Dacryodes edulis. Values are mean $\pm \mathrm{SEM}$ of six replicated; $\mathrm{CCl}_{4}$, carbon tetrachloride-intoxicated untreated rats, DET, carbon tetrachloride-intoxicated rats treated with ethanolic seed extract of D. edulis.

\subsection{Effects on serum enzymes.}

Significant $(p<0.05)$ increase in serum AST, ALT, and ALP activities were observed following a $72 \mathrm{~h} \mathrm{CCl}_{4}$-intoxication in rats.

However, serum AST activity was significantly $(p<0.05)$ reduced due to treatment with $1500 \mathrm{mg} / \mathrm{kg}$ ethanolic seed extract of D. edulis (DET) from day 7, and even to the control level starting from day 14 up to day 28 (Figure 2a) compared to $\mathrm{CCl}_{4}$ group.
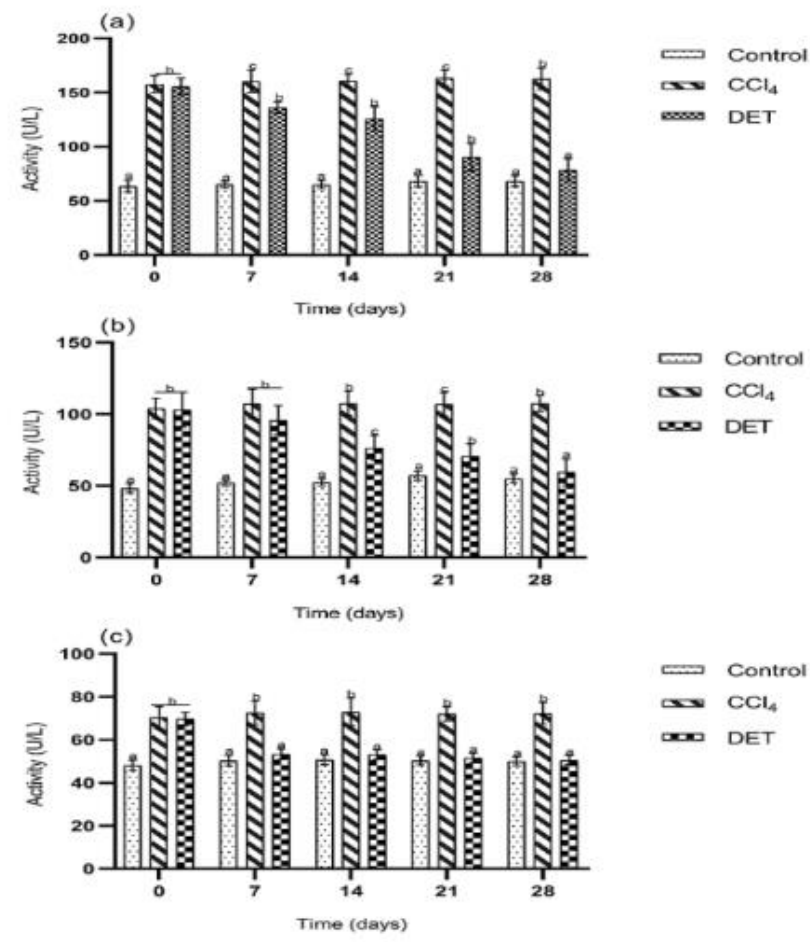

Control

$\infty \mathrm{CCl}_{1}$

$\infty$ DET

Figure 2. Serum (a) AST, (b) ALT, and (c) ALP activities in $\mathrm{CCl}_{4}$-intoxicated rats treated with ethanol seed extract of Dacryodes edulis. Values are mean \pm SEM of six replicated; Bars carrying different alphabets are significant at $p<0.05 ; \mathrm{CCl}_{4}$, carbon tetrachloride-intoxicated untreated rats, DET, carbon tetrachlorideintoxicated rats treated with ethanolic seed extract of $D$. edulis. 
Serum ALT activity was significantly $(p<0.05)$ restored to control value in $\mathrm{CCl}_{4}$ rats administered $1500 \mathrm{mg} / \mathrm{kg}$ ethanolic seed extract of $D$. edulis (DET) from day 14 to the last day of treatment, i.e., day 28 (Figure 2b) compared to $\mathrm{CCl}_{4}$ group. As observed with AST activity, ALP activity was restored to normal level due to treatment with $1500 \mathrm{mg} / \mathrm{kg}$ ethanolic seed extract of D. edulis (DET) from day 7 of treatment (Figure 2c).

Carbon tetrachloride exposure resulted in a significant $(p<0.05)$ increase in serum total and conjugated bilirubin concentration compared to control (Figure $3 \mathrm{a}$ and $\mathrm{b}$, respectively). Significant reduction in $(p<0.05)$ bilirubin concentration (total and conjugated) became noticeable starting from day 7 of treatment with $1500 \mathrm{mg} / \mathrm{kg}$ ethanolic seed extract of $D$. edulis compared to $\mathrm{CCl}_{4}$-induced but untreated rats.

Conversely, significant $(p<0.05)$ reduction in serum albumin and total protein concentrations (Figures $2 \mathrm{c}$ and $2 \mathrm{~d}$, respectively) were observed following a $72 \mathrm{~h} \mathrm{CCl}_{4}$ intoxication in $\mathrm{CCl}_{4}$-administered rats compared to control. However, following the administration of $1500 \mathrm{mg} / \mathrm{kg}$ ethanolic seed extract of D. edulis for 7 days and upwards (to day 28), a remarkable increase in serum albumin and total protein concentrations were observed in the $\mathrm{CCl}_{4}$-induced rats compared to $\mathrm{CCl}_{4}$-induced but untreated rats (Figure $3 \mathrm{c}$ and $\mathrm{d}$, respectively).
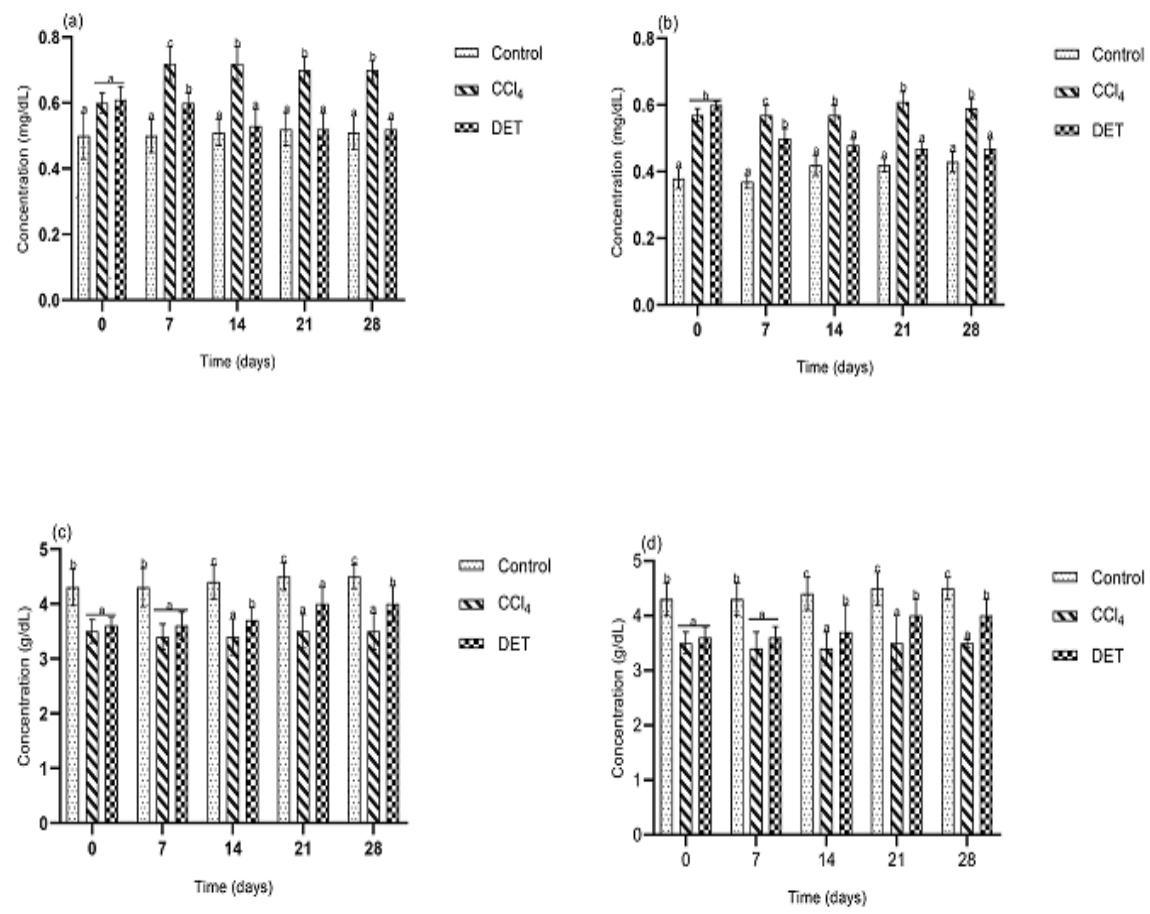

Figure 3. Serum (a) total bilirubin, (b) conjugated bilirubin, (c) albumin, and (d) total protein concentrations in $\mathrm{CCl}_{4}$-intoxicated rats treated with ethanol seed extract of Dacryodes edulis. Values are mean $\pm \mathrm{SEM}$ of six replicated; Bars carrying different alphabets are significant at $p<0.05 ; \mathrm{CCl}_{4}$, carbon tetrachloride-intoxicated untreated rats, DET, carbon tetrachloride-intoxicated rats treated with ethanolic seed extract of D. edulis.

\subsection{Effect on hepatocyte architecture.}

The liver section of the control rat showed normal cytoarchitectural features with distinct and intact hepatocytes (Figure 4A). Histological examination of animals induced with $\mathrm{CCl}_{4}$ presented necrotic hepatocyte nuclei (encircled), suggesting a persistent degenerative trend (Figure 4B). The liver section of DET rat showed semi-vacuolated hepatocyte nuclei but with more relatively intact cells, suggesting a reduced degenerative trend (Figure 4C). 


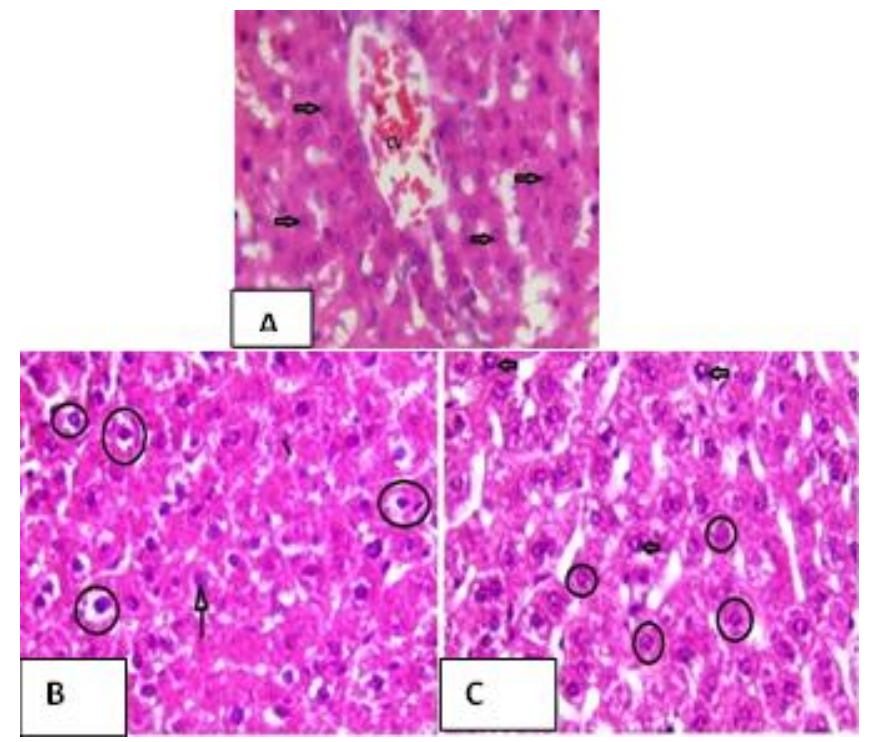

Figure 4. Effect of $\mathrm{CCl}_{4}$-intoxication on rat's hepatic histology. $\mathrm{CCl}_{4}$-intoxication induced severe pathological changes, including loss of cellular boundaries, necrotic hepatocyte nuclei (encircled), congested central vein, and damaged lobular (B). Treatment with $1500 \mathrm{mg} / \mathrm{kg}$ D.edulis ethanolic seed extract caused a reversal in $\mathrm{CCl}_{4^{-}}$ induced hepatic damage $(\mathrm{C})$.

\subsection{Discussion.}

The present study was designed to ascertain the potential restorative effects of $D$. edulis seed extract on $\mathrm{CCl}_{4}$-induced hepatotoxicity in male Wister rats. Chemicals, drugs, or infection through virus infiltration are known causes of liver tissue injury [25]. Animal model hepatotoxicity has been commonly achieved by carbon tetrachloride $\left(\mathrm{CCl}_{4}\right)$ exposure [26] and has been commonly employed for the evaluation of the protective potential of herbal extracts and drugs [14,16,25]. Carbon tetrachloride is metabolized first into trichloromethyl radical, a highly reactive species, which triggers protein oxidation and lipid peroxidation leading to hepatocellular toxicity. Through this mechanism, $\mathrm{CCl}_{4}$ depletes cellular antioxidant defenses, thus leading to oxidative stress $[13,14]$. The resultant functional and morphological changes in hepatocytes' membrane and the death of hepatocytes ultimately result in leakage of hepatic contents, including enzymes.

Serum activities of these enzymes, especially above the required serum levels most times, provide a good indication of the extent of liver damage [27-30]. Aminotransferases (ALT and AST) and ALP are membrane-bound enzymes that are majorly localized within hepatocytes; hence, they have most often been utilized as a diagnostic tool to ascertain the extent of damage to the liver. Damage to the membrane of hepatocytes can cause these enzymes to leak out, thereby leading to their elevation in the serum [27].

Observations from this study indicated that serum ALT, AST, and ALP activities, which were upregulated following a 3-day intoxication with $\mathrm{CCl}_{4}$ were considerably decreased after a 28-day treatment with $D$. edulis ethanolic seed extract, demonstrating a potential ability of the plant extract to abrogate liver damage possibly by a mechanism involving the restoration of membrane integrity via its antioxidant property. In addition, a remarkable improvement in food intake and body weight was observed in the extract-treated rats. Starvation has been reported to contribute to the generation of reactive oxygen species [31]. Reports from previous studies have demonstrated the antioxidant activity of ethanolic seed extract of D. edulis through the suppression of $\mathrm{CCl}_{4}$-induced oxidative stress in rats [14,16,32]. The presence of antioxidants phytochemicals such as flavonoids $D$. edulis seed extract has been reported by 
Oboh et al. [33] and Atawodi et al. [34]. According to reports from several studies, D. edulis fruits are potent sources of antioxidant molecules, including but not limited to polyphenolic compounds $[33,35]$ with several documented biological and pharmacological activities, such as antidiabetic, antimicrobial, antioxidant, and anti-inflammatory activities [34,36,37].

Furthermore, the reduction in serum total protein and albumin concentrations following a $72 \mathrm{~h} \mathrm{CCl}_{4}$-intoxication is in agreement with earlier observations by several authors $[13,15]$. Carbon tetrachloride poisoning has been established to cause intracellular alterations in protein synthesis in rats. A recent study by Iseghohi and Orhue [38] showed a significant decrease in serum total protein and albumin levels in rats administered $\mathrm{CCl}_{4}$. Albumin is synthesized mainly in the liver. Thus, a reduced albumin concentration is suggestive of a decrease in the rate of synthesis by the liver vis-à-vis an augmented rate of clearance or uptake. The concentration or amount of albumin in the serum is most often used to access the synthetic function of the liver. Therefore, the harmful effect of $\mathrm{CCl}_{4}$ on the liver is not limited to morphological alterations alone but also impact on its synthetic function. Hence, the reduction in serum albumin concentration, as reported in this study, is indicative of a possible compromise in the synthetic capacity of the liver [39]. Carbon tetrachloride is reported to cause disruption and disassociation of polyribosomes on the endoplasmic reticulum, thus, leading to a decrease in biosynthesis of protein [40]. Data obtained in this study showed that ethanolic seed extract of $D$. edulis resulted in a significant elevation in serum total protein and albumin in $\mathrm{CCl}_{4}$-intoxicated rats. The rise in total protein and albumin levels in $\mathrm{CCl}_{4}$-intoxicated rats as a result of treatment with $D$. edulis ethanolic seed extract observed in this study is indicative of a restorative potential of the extract on damaged liver cells. This observation is in consonance with the reports from previous studies by Ononamadu et al. [41] and Iseghohi and Orhue [14].

The seeming repairs and restorative potential of $D$. edulis ethanolic seed extract on $\mathrm{CCl}_{4}$-induced liver damage, as inferred from the results of serum biochemical analyses in this study, is further reinforced by the histopathological examination of liver sections. Severe histological alterations, including crowding in a central vein, damaged lobular architecture, and leucocyte infiltration, were observed in $\mathrm{CCl}_{4}$-intoxicated but untreated rats. However, these changes were remarkably mitigated in $\mathrm{CCl}_{4}$-intoxicated rats treated with $D$. edulis ethanolic seed extract for 28 days.

\section{Conclusions}

In conclusion, data obtained in this study showed that $\mathrm{CCl}_{4}$-induced hepatotoxicity in rats was supported by reduced body weight, elevated serum enzyme activities, increased serum total and conjugated bilirubin concentrations, reduced serum albumin, and total protein concentrations, which taken together provide an indication of structural and functional deficiencies of the liver. These evidence were further strengthened by the histological disruption in hepatocyte architecture. On the other hand, in $\mathrm{CCl}_{4}$-intoxicated rats treated with D. edulis ethanolic seed extract at $1500 \mathrm{mg} / \mathrm{kg}$ body weight, remarkable improvements in serum levels of these hepatic function indicators suggestive of possible repair mechanism and restoration of function.

\section{Funding}

This study was funded through individual contributions by the authors. 


\title{
Acknowledgments
}

\section{The authors wish to appreciate the technical supports from the technical staff of the Department of Applied Biochemistry, Nnamdi Azikwe University, Akwa, Anambra State, Nigeria.}

\section{Conflicts of Interest}

\author{
The authors declare no conflict of interest.
}

\section{References}

1. Varghese, J.F.; Patel, R.; Yadav, U. Novel insights in the metabolic syndrome-induced oxidative stress and inflammation-mediated atherosclerosis. Curr Cardiol Rev 2018, 14, 4-14, https://dx.doi.org/10.2174\%2F1573403X13666171009112250.

2. Chen, M.; Li, X.; Shi, Q.; Zhang, Z.; Xu, S. Hydrogen sulfide exposure triggers chicken trachea inflammatory injury through oxidative stress-mediated FOS/IL8 signaling. J Hazard Mater 2019, 368, 24354, https://doi.org/10.1016/j.jhazmat.2019.01.054.

3. Sies, H.; Jones, D.P. Reactive oxygen species (ROS) as pleiotropic physiological signalling agents. Nat Rev Mol Cell Biol 2020, 21, 363-383, https://doi.org/10.1038/s41580-020-0230-3.

4. Anglada, J.M.; Crehuet, R.; Adhikari, S.; Francisco, J.S.; Xia, Y. Reactivity of hydropersulfides toward the hydroxyl radical unraveled: disulfide bond cleavage, hydrogen atom transfer, and proton-coupled electron transfer. Phys Chem Chem Phys 2018, 20, 4793-4804, https://doi.org/10.1039/c7cp07570g.

5. Song, Y.; Li, S.; Geng, W.; Luo, R.; Liu, W.; Tu, J.; Wang, K.; Kang, L.; Yin, H.; Wu, X.; Gao, Y. Sirtuin 3-dependent mitochondrial redox homeostasis protects against AGEs-induced intervertebral disc degeneration. Redox Biol 2018, 19, 339-353, https://doi.org/10.1016/j.redox.2018.09.006.

6. Yu, W.; Tao, M.; Zhao, Y.; Hu, X.; Wang, M. 4'-Methoxyresveratrol alleviated AGE-induced inflammation via RAGE-mediated NF- $\mathrm{B}$ and NLRP3 inflammasome pathway. Molecules 2018, 23, https://doi.org/10.3390/molecules23061447.

7. Green, K.N.; Pota, K.; Tircsó, G.; Gogolák, R.A.; Kinsinger, O.; Davda, C.; Blain, K.; Brewer, S.M.; Gonzalez, P.; Johnston, H.M.; Akkaraju, G. Dialing in on pharmacological features for a therapeutic antioxidant small molecule. Dalton Trans 2019, 48, 12430-12439, https://doi.org/10.1039/C9DT01800J.

8. Oluba, O.M.; Akpor, O.B.; Adebiyi, F.D.; Josiah, S.J.; Alabi, O.O.; Shoyombo, A.O.; Olusola, A.O. Effects of co-administration of Ganoderma terpenoid extract with chloroquine on inflammatory markers and antioxidant status in Plasmodium berghei-infected mice. $J$ Integr Med 2020, https://doi.org/10.1016/j.joim.2020.08.002.

9. Oluba, O.M.,; Adebiyi, F.D.; Dada, A.A.; Ajayi, A.A.; Adebisi, K.E.; Josiah, S.J.; Odutuga, A.A. Effects of Talinum triangulare leaf flavonoid extract on streptozotocin-induced hyperglycemia and associated complications in rats. Food Sci Nutr 2019, 7, 385-394, https://doi.org/10.1002/fsn3.765.

10. Okunomo, K.; Egho, E.O. Economic importance of some underexploited tree species in Nigeria: urgent need for separate research centers. Cont J Biol Sci 2010, 3, 16-32.

11. Ajibesin, K.K. Dacryodes edulis (G. Don) HJ Lam: a review on its medicinal, phytochemical and economical properties. Res J Med Plant 2011, 5, 32-41, https://doi.org/10.3923/rjmp.2011.32.41.

12. Okwu, D.E.; Nnamdi, F.U. Evaluation of the chemical composition of Dacryodes edulis and Raphia hookeri Mann and Wendl exudates used in herbal medicine in south eastern Nigeria. Afr J Tradit Complem 2008, 5, 194-200, https://doi.org/10.4314/ajtcam.v5i2.31273.

13. Gutyj, B.; Martyshchuk, T.; Bushueva, I.; Semeniv, B.; Parchenko, V.; Kaplaushenko, A.; Magrelo, N.; Hirkovyy, A.; Musiy, L.; Murska, S. Morphological and biochemical indicators of blood of rats poisoned by carbon tetrachloride and subject to action of liposomal preparation. Regulatory Mech Biosys 2017, 2, https://doi.org/10.15421/021748.

14. Orhue, N.E.; Adaikpoh, M.A.; Okuo, V.A.; Iseghohi, S.O. Ethanol extract of Dacryodes edulis seeds suppresses carbon tetrachloride-induced liver damage in Wistar albino rats. Effect of Nigerian medicinal plants on damaged organs in laboratory animals $\mathbf{2 0 1 7}, 15$.

15. Jia, R.; Cao, L.; Xu, P.; Jeney, G.; Yin, G. In vitro and in vivo hepatoprotective and antioxidant effects of Astragalus polysaccharides against carbon tetrachloride-induced hepatocyte damage in common carp (Cyprinus carpio). Fish Physiol Biochem 2012, 38, 871-881, https://doi.org/10.1007/s10695-011-9575-z.

16. Orhue, N.E.J.; Adaikpoh, M.A.; Odude, O.; Iseghohi, S.O. Prevention of carbon tetrachloride-induced hepatic steatosis and cellular damage by aqueous extract of Dacryodes edulis seeds in Wistar rats. Bio-Res 2015, 13, 885-888, https://doi.org/10.4314/br.v13i1.144795.

17. National Research Council. Guide for the care and use of laboratory animals. National Academies Press. 2010.

18. Lorke, D. A new approach to practical acute toxicity testing. Arch Toxicol 1983, 54, 275-287, https://doi.org/10.1007/BF01234480. 
19. Bowers Jr. G.N.; McComb, R.B. Measurement of total alkaline phosphatase activity in human serum. Clin Chem 1975, 21, 1988-95, https://doi.org/10.1093/clinchem/21.13.1988.

20. Reitman, S.; Frankel, S. A colorimetric method for the determination of serum glutamic oxalacetic and glutamic pyruvic transaminases. Am J Clin Pathol 1957, 28, 56-63, https://doi.org/10.1093/ajcp/28.1.56.

21. Perry, B.; Doumas, B.T.; Buffone, G.; Glick, M.; Ou, C.N.; Ryder, K. Measurement of total bilirubin by use of bilirubin oxidase. Clin Chem 1986, 32, 329-332.

22. Kurosaka, K.; Senba, S.; Tsubota, H.; Kondo, H. A new enzymatic assay for selectively measuring conjugated bilirubin concentration in serum with use of bilirubin oxidase. Clin Chim Acta 1998, 269, 125136, https://doi.org/10.1016/s0009-8981(97)00194-0.

23. Ohnishi, S.T.; Barr, J.K. A simplified method of quantitating protein using the biuret and phenol reagents. Analytical Biochem 1978, 86, 193-200, https://doi.org/10.1016/0003-2697(78)90334-2.

24. Ueno, T.; Hirayama, S.; Ito, M.; Nishioka, E.; Fukushima, Y.; Satoh, T.; Idei, M.; Horiuchi, Y.; Shoji, H.; Ohmura, H.; Shimizu, T. Albumin concentration determined by the modified bromocresol purple method is superior to that by the bromocresol green method for assessing nutritional status in malnourished patients with inflammation. Ann Clin Biochem 2013, 50, 576-584, https://doi.org/10.1177/0004563213480137.

25. Oluba, O.M.; Onyeneke, E.C.; Ojieh, G.C.; Idonije, B.O.; Ojiezeh, T.I. Hepatoprotective potential of aqueous extract of Ganoderma lucidum against carbon tetrachloride intoxication in rats. Der Pharmacia Lettre 2010, 2, 432-9.

26. Wang, T.; Sun, N.L.; Zhang, W.D.; Li, H.L.; Lu, G.C.; Yuan, B.J.; Jiang, H.; She, J.H.; Zhang, C. Protective effects of dehydrocavidine on carbon tetrachloride-induced acute hepatotoxicity in rats. J Ethnopharmacol 2008, 117, 300-308, https://doi.org/10.1016/j.jep.2008.02.010.

27. Oluba, O.M.; Adeyemi, O.; Ojieh, G.C.; Adebisi, K.E.; Isiosio, I.O.; Aboluwoye, C.O. Effect of dietary cholesterol on some serum enzymes. J Med Sci 2008, 8, 390-394, https://doi.org/10.3923/jms.2008.390.394.

28. Oluba, O.M.; Adebiyi, F.D.; Dada, A.A.; Ajayi, A.A.; Adebisi, K.E.; Josiah, S.J.; Odutuga, A.A. Effects of Talinum triangulare leaf flavonoid extract on streptozotocin-induced hyperglycemia and associated complications in rats. Food Sci Nutr 2019, 7, 385-394, https://doi.org/10.1002/fsn3.765.

29. Oluba, O.M.; Adebisi, K.E.; Eidangbe, G.O.; Odutuga, A.A.; Onyeneke, E.C. Modulatory Effect of Crude Aqueous Extract of Lingzhi or Reishi Medicinal Mushroom, Ganoderma lucidum (Higher Basidiomycetes), on Hematological and Antioxidant Indices in Plasmodium berghei- infected Mice. Int J Med Mushr 2014, 16, https://doi.org/10.1615/intjmedmushrooms.v16.i5.90.

30. Idonije, B.O.; Nwoke, E.O.; Festus, O.; Oluba, O.M. Plasma concentrations of kidney function indicators in malaria patients in Ekpoma, South-South Nigeria. Int $J$ Trop Med 2011, 6, 4-7, http://dx.doi.org/10.3923/ijtmed.2011.4.7.

31. Lalaouna, D.; Baude, J.; Wu, Z.; Tomasini, A.; Chicher, J.; Marzi, S.; Vandenesch, F.; Romby, P.; Caldelari, I.; Moreau, K. RsaC sRNA modulates the oxidative stress response of Staphylococcus aureus during manganese starvation. Nucleic acids Res 2019, 47, 9871-9887, https://doi.org/10.1093/nar/gkz728.

32. Zhi, Q.; Li, Y.; Li, F.; Tian, Y.; Li, F.; Tang, Y.; Yang, Y.; Yin, R.; Ming, J. Polyphenols extracted from Coreopsis tinctoria buds exhibited a protective effect against acute liver damage. J Funct Foods 2018, 44, 201-208, https://doi.org/10.1016/j.jff.2018.03.019.

33. Oboh, G.; Ademosun, A.O.; Olasehinde, T.A.; Oyeleye, S.I.; Ehiakhamen, E.O.Effect of processing methods on the antioxidant properties and inhibition of $\alpha$-amylase and $\alpha$-glucosidase by African pear (Dacryodes edulis) fruit. Nutrafoods 2015, 14, 19-26, https://doi.org/10.1007/s13749-014-0065-7.

34. Atawodi, S.E.; Atawodi, J.C.; Idakwo, P.; Pfundstein, B.; Haubner, R.; Wurtele, G.; Spiegelhalder, B.; Bartsch, H.; Owen, R.W. Evaluation of the polyphenol composition and antioxidant activity of African variety of Dacryodes edulis (G. Don) HJ Lam fruit. $J$ Med Food 2009, 12, 1321-5, https://doi.org/10.1089/jmf.2008.0215.

35. Erukainure, O.L.; Mopuri, R.; Oyebode, O.A.; Koorbanally, N.A.; Islam, M.S. Dacryodes edulis enhances antioxidant activities, suppresses DNA fragmentation in oxidative pancreatic and hepatic injuries; and inhibits carbohydrate digestive enzymes linked to type 2 diabetes. Biomed Pharmacother 2017, 96, 37-47, https://doi.org/10.1016/j.biopha.2017.09.106.

36. Olivier, T.T.; Moïse, F.; Jackson, S.A.; Francis, N.T. A review on traditional uses, phytochemical and pharmacological profiles, spiritual and economic values, and toxicity of Dacryodes edulis (g. Don) hj Lam. J Drug Deliv Ther 2016, 6, 84-90, https://doi.org/10.22270/jddt.v6i5.1276.

37. Erukainure, O.L.; Ijomone, O.M.; Chukwuma, C.I.; Xiao, X.; Salau, V.F.; Islam, M.S. Dacryodes edulis (G. Don) HJ Lam modulates glucose metabolism, cholinergic activities and Nrf2 expression, while suppressing oxidative stress and dyslipidemia in diabetic rats. $J$ Ethnopharmacol 2020, 255, https://doi.org/10.1016/j.jep.2020.112744.

38. Iseghohi, S.O.; Orhue, N.E. Aqueous extract of Dennettia tripetala ameliorates liver and kidney damage caused by multiple exposures to carbon tetrachloride. Clin Phytosci 2017, 3, https://doi.org/10.1186/s40816017-0043-X.

39. Chiang, Y.Y.; Chao, J.C.J. Olive oil combined with Lycium barbarum polysaccharides attenuates liver apoptosis and inflammation induced by carbon tetrachloride in rats. J Funct Foods 2018, 48, 329-336, https://doi.org/10.1016/j.jff.2018.07.029. 
40. Wu, T.; Shen, M.; Liu, S.; Yu, Q.; Chen, Y.; Xie, J. Ameliorative effect of Cyclocarya paliurus polysaccharides against carbon tetrachloride induced oxidative stress in liver and kidney of mice. Food Chem Toxicol 2020, 135, https://doi.org/10.1016/j.fct.2019.111014.

41. Ononamadu, C.J.; Alhassan, A.J.; Ibrahim, A.; Imam, A.A.; Ihegboro, G.O.; Owolarafe, A.T.; Ezeigwe, C.O.; Atiku, M.K.; Sule, M.S. Toxicological study of aqueous-methanol solvent fraction of methanol extract of Dacryodes edulis leaves. Toxicol Rep 2020, 7, 909-918, https://doi.org/10.1016/j.toxrep.2020.07.007. 